\title{
Pott's Disease
}

\section{Saranapoom Klomjit MD, Hawa Edriss MD}

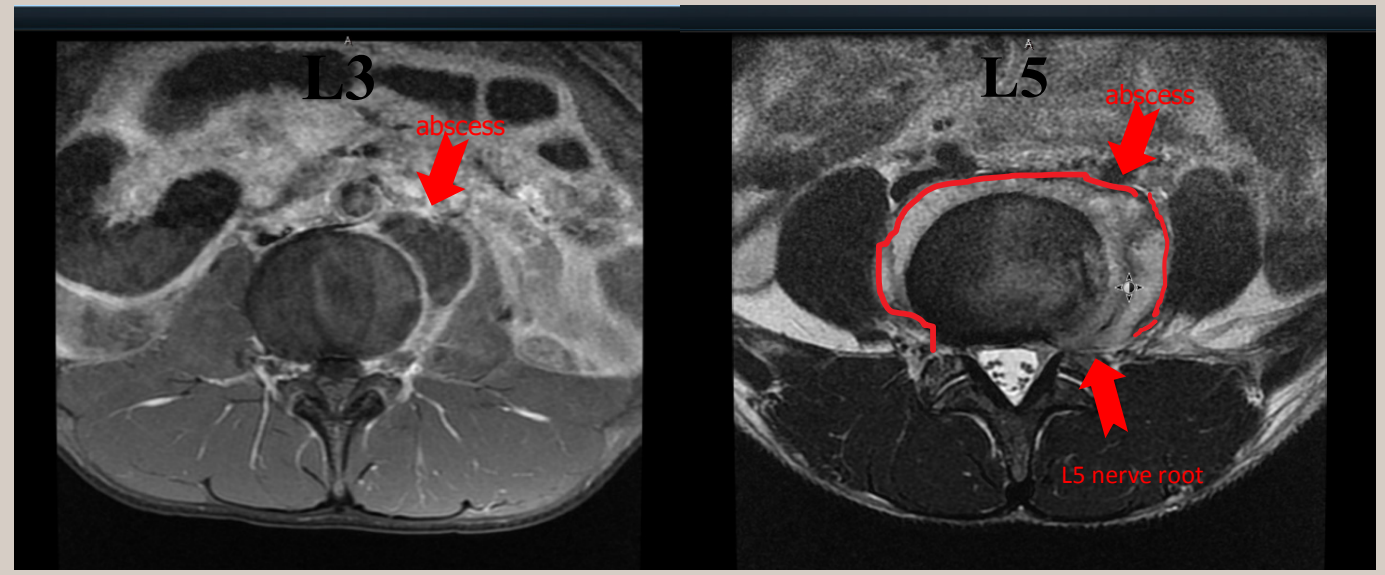

Figure 1. MRI spine. There is a $2.1 \times 3.2 \mathrm{~cm}$ left paraspinal abscess on L3-4 and ill-defined enhancing fluid collection/abscess in the pre and paraspinal regions of $L 5$ extending along the neural foramen causing mild bilateral neural foraminal narrowing

A 21-year-old man with no significant past medical history came to the emergency department with abdominal pain. He stated he had intermittent back pain, abdominal pain, and a 35 pound unintentional weight loss over the past year. He denied any recent travel. He admitted that he was exposed to tuberculosis a year and a half ago through a friend in college who was diagnosed with pulmonary tuberculosis. His physical examination was unremarkable.

Laboratory tests included an elevated erythrocyte sedimentation rate $(35 \mathrm{~mm} / \mathrm{h})$ and C-reactive protein $(14.1 \mathrm{mg} / \mathrm{L})$. His HIV test was negative; his QuantiFERON-TB Gold In-Tube was positive at $>0.35$

Corresponding author: Saranapoom Klomjit MD Contact Information: saranapoom.klomjit@ttuhsc.edu DOI: 10.12746/swrccc2014.0206.073

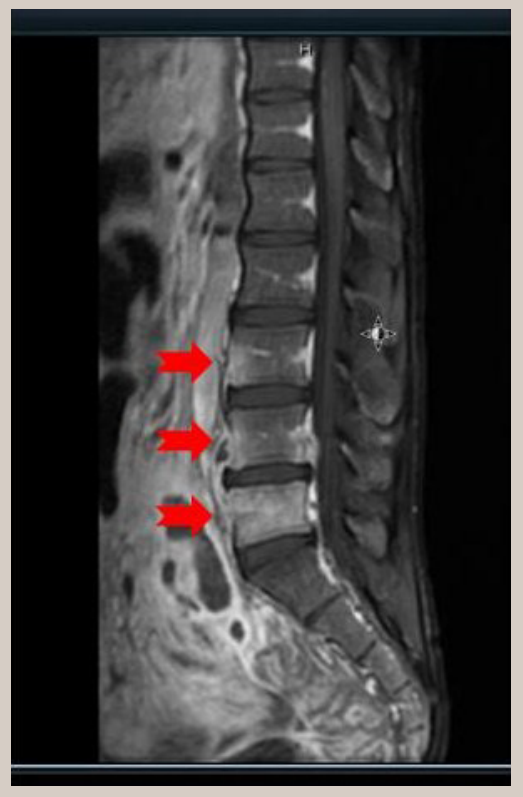

Figure 2. Abnormal enhancement at anterior aspect of $L 3$ and $L 4$ vertebral bodies and abnormal enhancement in the left half of the $L 5$ vertebral body extending to the pedicle, transverse, and articular processes of L3-L5 
$\mathrm{IU} / \mathrm{ml}$. This assay is an interferon-gamma release assay (IGRA) and has a normal cut off $<0.35 \mathrm{IU} / \mathrm{ml}$. His chest $\mathrm{X}$-ray showed small bilateral pleural effusions. A $\mathrm{MRI}$ of the spine is shown in Figures 1 and 2. A surgical procedure with fluoroscopically guided spinal biopsy and aspiration using an 18 gauge Chiba needle recovered 30 milliliters of pus near the left L4 vertebral body. Laboratory tests included an AFB stain of the fluid with 1+ acid-fast bacilliusing the Ziehl-Neelsen method and a positive culture and PCR for Mycobacterium tuberculosis from the aspiration fluid.

\section{Discussion}

Spinal tuberculosis is the most common skeletal tuberculosis and accounts for $50 \%$ of all cases. The hematogenous dissemination to the culprit spine probably explains the pathogenesis of the disease. ${ }^{2}$ The thoracolumbar spine is the most common site, and the infection often spreads longitudinally adjacent to the vertebral bodies. ${ }^{1,3}$ Back pain is the most common symptom. Nonspecific complaints, such as fever and weight loss, frequently occur. Neurologic deficits develop in some cases. ${ }^{3,4}$ Our patient presented with abdominal pain which is atypical for spinal tuberculosis. He had a positive QuantiFERON assay. This is a diagnostic test for TB infection and measures the cell-mediated response to specific $M$. tuberculosis antigens. It cannot distinguish latent TB infection from active tuberculosis disease (which usually requires a microbiological diagnosis). A positive QFT test result does not necessarily indicate active TB, but a negative IGRA significantly reduces the possibility of both active and latent tuberculosis. The test is not affected by prior bacille Calmette-Guérin vaccination. ${ }^{5}$ It has a sensitivity of $84 \%$ and the specificity of $95 \%$ in patients with spinal TB. ${ }^{6}$ Approximately $70 \%$ of patients with spinal tuberculosis have a history of pulmonary tuberculosis or radiographic findings consistent with pulmonary tuberculosis. Our patient had small pleural effusions on his chest $x$-ray. Plain bone films can identify skeletal infection in patients with advanced disease, and typical radiographic findings include osteolysis of vertebral endplates, loss of disc height, osseous destruction, new bone formation, and soft tissue abscess. CT scans provide more information about the bony destruction and identify the paraspinal abscesses better. MRI studies can provide more information about neural involvement and can detect spinal cord infection, spinal cord cavitation, and spinal cord compression. ${ }^{6-9}$ Our patient had osteomyelitis of L3-L5 and paravertebral abscesses. Microbiological and histological tests provide the most definitive diagnosis. ${ }^{6,10}$ He had positive stains and cultures, was treated with isoniazid, pyrazinamide, ethambutol, and rifampin, and had a good initial clinical response.

Recieved : 02/21/2014

Accepted : 04/04/2014

Reviewers : Kenneth Nugent MD

Published electronically : 04/15/2014

\section{REFERENCES}

1. Tuli SM. General principles of osteoarticular tuberculosis. Clinical orthopaedics and related research 2002; 398:11-9.

2. Tuli SM. Tuberculosis of the spine: a historical review. Clinical orthopaedics and related research 2007; 460:29-38.

3. Fuentes Ferrer M, Gutierrez Torres L, Ayala Ramirez O, Rumayor Zarzuelo M, del Prado Gonzalez N. Tuberculosis of the spine. A systematic review of case series. International orthopaedics 2012;36(2):221-31.

4. Nussbaum ES, Rockswold GL, Bergman TA, Erickson DL, Seljeskog EL. Spinal tuberculosis: a diagnostic and management challenge. J Neurosurg 1995;83(2):243-7.

5. Clinicians guide to QuantiFERON-TB. Cellestis Inc. November 2001, accessed 3/28.2014.

6. Garg RK, Somnanshi DS. Spinal tuberculosis; a review. J Spinal Cord Med 2011;34: 440-454.

7. LaBerge JM, Brant-Zawadzki M. Evaluation of Pott's disease with computed tomography. Neuroradiology 1984;26(6):429-34. 8. Ridley N, Shaikh MI, Remedios D, Mitchell R. Radiology of 
skeletal tuberculosis. Orthopedics 1998;21(11):1213-20.

9. Zaidi H, Akram MH, Wala MS. Frequency and magnetic resonance imaging patterns of tuberculous spondylitis lesions in adults. J Coll Phys Surg--Pakistan : JCPSP 2010;20(5):303-6.

10. Pertuiset E, Beaudreuil J, Liote F, Horusitzky A, Kemiche F, Richette P, et al. Spinal tuberculosis in adults. A study of 103 cases in a developed country, 1980-1994. Medicine 1999;78(5):30920 . 